\title{
Comment on "Comparison of ozone measurement methods in biomass burning smoke: an evaluation under field and laboratory conditions" (Long et al. 2021)
}

\author{
Noah Bernays ${ }^{1}$, Daniel A. Jaffe ${ }^{1,2}$, Irina Petropavlovskikh ${ }^{3}$, Peter Effertz ${ }^{4}$
}

$5 \quad{ }^{1}$ School of STEM, University of Washington, Bothell, WA 98011, U.S.A.

${ }^{2}$ Department of Atmospheric Sciences, University of Washington, Seattle, WA 98195, U.S.A.

${ }^{3}$ NOAA Global Monitoring Laboratory, Boulder, Colorado 80305, U.S.A

${ }^{4}$ CIRES, University of Colorado, Boulder, CO 80309, U.S.A.

Correspondence to: Daniel A. Jaffe (djaffe@uw.edu)

Abstract

Long et al (2021) conducted a detailed study of possible interferents in measurements of surface $\mathrm{O}_{3}$ by UV spectroscopy, which measures the UV transmission in ambient and $\mathrm{O}_{3}$ scrubbed air. While we appreciate the careful work done in this analysis, there were several omissions and, in one case, the type of scrubber used was misidentified as manganese dioxide $\left(\mathrm{MnO}_{2}\right)$, when in fact it was manganese chloride $\left(\mathrm{MnCl}_{2}\right)$. This misidentification led to the erroneous conclusion that all UV-based $\mathrm{O}_{3}$ instruments employing solid-phase catalytic scrubbers exhibit significant positive artifacts, whereas previous research found this not to be the case when employing $\mathrm{MnO}_{2}$ scrubber types. While the Long study, and our results, confirm the substantial bias in instruments employing an $\mathrm{MnCl}_{2}$ scrubber, a replication of the earlier work with an $\mathrm{MnO}_{2}$ scrubber type and no humidity correction is needed.

\section{Introduction}

Ozone $\left(\mathrm{O}_{3}\right)$ is a key hazardous atmospheric pollutant. In the U.S., more than 100 million people live in regions that do not meet the National Ambient Air Quality Standards. Wildfires exacerbate $\mathrm{O}_{3}$ pollution (Jaffe et al 2013; 2020; Brey and Fischer 2016; Gong et al 2017). Given that smoke contains literally hundreds of compounds, it is important to address possible interferences in measurements of $\mathrm{O}_{3}$. Long et al (2021) conducted a detailed study of possible interferences in UV measurements of $\mathrm{O}_{3}$, the most commonly used method. In the $\mathrm{UV}$ method, $\mathrm{O}_{3}$ is measured at $254 \mathrm{~nm}$ in a sample airstream and in an airstream where $\mathrm{O}_{3}$ has been removed, usually by a solid-state catalytic scrubber. Long et al provide an excellent discussion of this method, which we won't repeat here. However, one of the most important aspects in this measurement is the nature of the scrubber that is used to remove $\mathrm{O}_{3}$. For the scrubber, various companies have used manganese dioxide $\left(\mathrm{MnO}_{2}\right)$, Hopcalite (a mixture of manganese and copper oxides) and manganese chloride $\left(\mathrm{MnCl}_{2}\right)$. Long et al compared multiple UV instruments with an NO chemiluminescence instrument, a method which is presumably free from interferences. Long et al found a significant bias of 16-24 ppb $\mathrm{O}_{3}$ per ppm of $\mathrm{CO}$ in one type of $\mathrm{UV} \mathrm{O}_{3}$ analyzer (Thermo-Fisher 49i) that was tested 
without humidity correction, as compared to the NO-chemiluminescence method. The bias was correlated with smoke tracers, such as $\mathrm{CO}$ and total hydrocarbons. Other instruments were tested with a humidity correction and found to have a much smaller bias which Long et al attributed to the humidity correction. According to Long et al, the scrubber types on these instruments were similar, but in fact they were not, as discussed below, and this leads to significant uncertainty with their conclusions.

Long et al. did not cite our earlier study (Gao et al. 2017). In this work, we conducted a comparison between two UV-based $\mathrm{O}_{3}$ analyzers (Dasibi 1008-RS and Ecotech Serinus 10) and an NO-chemiluminescent analyzer in wildfire plumes at the Mt. Bachelor Observatory (MBO) during the 2015 wildfire season. Gao found no significant bias in the UV analyzers relative to the NO-chemiluminescent analyzer in moderate smoke plumes, up to approximately 1 ppm of carbon monoxide (CO). Both of these UV analyzers used an $\mathrm{MnO}_{2}$ scrubber. The detailed methods used in Gao's study along with the quality assurance and quality control steps are outlined in the paper and we believe these were sufficient to meet the study's objectives. A key question is: why were Long et al's results different from Gao et al's results? We address this question below.

\section{Scrubber type misidentified}

Long cites the Thermo-Fisher Scientific Model 49i series instrument's scrubber type as $\mathrm{MnO}_{2}$ (as do others: Turnipseed 2017; Spicer 2010; Kleindienst 1993). However, according to a representative from the Thermo-Fisher company, the scrubbers in the $49,49 \mathrm{c}$, and $49 \mathrm{i}$ series use $\mathrm{MnCl}_{2}$, not $\mathrm{MnO}_{2}$. This was confirmed on four separate occasions by the manufacturer. This instrument was the only one used by Long et al with no humidity correction, which is the most common way these instruments are deployed.

\section{Recent data from the Mt. Bachelor Observatory confirm bias with $\mathrm{MnCl}_{2}$ scrubber type}

Starting in 2018, we have deployed two $\mathrm{O}_{3}$ instruments at the MBO, the Ecotech Serinus 10, previously used in the Gao et al study, and a Thermo-Fisher 49c, a similar instrument to the one used in Long's study which uses the same scrubber and no humidity correction. Generally, the Ecotech and Thermo-Fisher instruments agree well, but in a particularly strong period of wildfire smoke, we saw a substantial difference in the two measurements. Figure 1 shows data from a 3-week period in September-October 2020, when we experienced heavy smoke at the MBO. The slope (.0116 ppb of $\mathrm{O}_{3}$ per ppb $\mathrm{CO}$ ) is smaller but of the same order of magnitude as that reported by Long et al for comparisons of the Thermo-Fisher to the NO-chemiluminescent instrument (.016-.024 ppb $\mathrm{O}_{3}$ per ppb CO). It is possible that the Ecotech also has a small degree of bias, which would explain the smaller slope compared to

60 Long's, but it would have to be much smaller than the bias observed in the Thermo-Fisher instrument during the high CO events in 2020. Given our earlier comparison with the Ecotech instrument, we contend that this corroborates Long's conclusion that the Thermo-Fisher instrument exhibits a significant positive bias at high CO 
levels. We believe the $\mathrm{MnCl}_{2}$ scrubber in the $49 \mathrm{i}$ is the primary cause for the discrepancy between Long and Gao's findings.

\section{Nafion dryer vs. scrubber impacts on $\mathrm{O}_{3}$ measurements: need for further research}

When Long et al put a Nafion dryer on their Thermo-Fisher instrument midway through the study, the bias was reduced by an order of magnitude. We agree with Long et al that the Nafion dryer reduced not only water vapor, but also probably scrubbed many of the VOC's that were causing the bias. While Nafion is known to transfer $\mathrm{O}_{3}$ and lower molecular weight alkanes efficiently, it will remove more complex VOC's that are likely responsible for the bias in UV instruments (Perma-Pure 2022). Similar tests with/without a Nafion drier were not done for the other instruments. The Nafion-dried 2B-205 instrument in Long's study showed $\mathrm{O}_{3}$ artifacts an order of magnitude lower than the non-dried UV analyzers, but this can be explained by the 2B's $\mathrm{MnO}_{2}$-containing Hopcalite scrubber acting similarly to a pure $\mathrm{MnO}_{2}$ scrubber. We note that current EPA recommendations are to include Nafion dryers for UV $\mathrm{O}_{3}$ instruments (Halliday et al 2020), and we see no downside to this recommendation. But given that this remains a recommendation, and to interpret past data, we suggest that future experiments include instruments with a true $\mathrm{MnO}_{2}$ scrubber with, and without, humidity correction, as this is the most common field setup.

\section{Data availability}

Data from the Mt. Bachelor Observatory are archived at the University of Washington's Research Works Archive (https://digital.lib. washington.edu/researchworks/discover?scope $=\% 2 \mathrm{~F} \&$ query $=\% 22 \mathrm{mt}$.+bachelor+observatory $\% 22$ $\&$ submit=\&filtertype_0=title\&filter_relational_operator_0=contains\&filter_0=data).

\section{Acknowledgements}

The Mt. Bachelor Observatory is supported by the National Science Foundation (grant \#AGS-1447832) and the National Oceanic and Atmospheric Administration (contract \#RA-133R-16-SE-0758).

\section{References}

85 Brey, S. J. and Fischer, E.V.: Smoke in the city: how often and where does smoke impact summertime ozone in the United States?, Environ. Sci. Technol., 50, 1288-1294, ttps://doi.org/10.1021/acs.est.5b05218, 2016.

Gao, H. and Jaffe, D.A.: Comparison of ultraviolet absorbance and NO-chemiluminescence for ozone measurement in wildfire plumes at the Mount Bachelor Observatory, Atmos. Environ., 166, 224-233, https://doi.org/10.1016/j.atmosenv.2017.07.007, 2017. 
Gong X., Kaulfus, A., Nair, U., and Jaffe, D.A: Quantifying $\mathrm{O}_{3}$ impacts in urban areas due to wildfires using a generalized additive model, Environ. Sci. Technol., 51 (22), 13216-13223, 10.1021/acs.est.7b03130, 2017.

Halliday, H., C. Johnson, R. Long, R. Vanderpool, and A. Whitehill. Recommendations for Nationwide Approval of Nafion $^{\mathrm{TM}}$ Dryers Upstream of UV-Absorption Ozone Analyzers. U.S. Environmental Protection Agency, Washington, DC, EPA/600/R-20/390, 2020.

Jaffe, D.A., Wigder, N., Downey, N., Pfister, G., Boynard, A., and Reid, S.B.: Impact of wildfires on ozone exceptional events in the western U.S., Environ. Sci. Technol., 47 (19), 11065-11072, 10.1021/es402164f, 2013.

Jaffe, D.A., O’Neill, S.M., Larkin, N.K., Holder, A.L, Peterson, D.L., Halofsky, J.E., and Rappold, A.G.: Wildfire and prescribed burning impacts on air quality in the United States, J. Air Waste Manage., 70 (6), 583 —615, 10.1080/10962247.2020.1749731, 2020.

Kleindienst, T.E., Hudgens, E.E., Smith, D.F., McElroy, F.F., and Bufalini, J.J.: Comparison of chemiluminescence and ultraviolet ozone monitor responses in the presence of humidity and photochemical pollutants, J. Air Waste Manage., 43, 213-222, https://www.tandfonline.com/doi/pdf/10.1080/1073161X.1993.10467128, 1993.

Long, R.W., Whitehill, A., Habel, A., Urbanski, S., Halliday, H., Colón, M., Kaushik, S., and Landis, M.S.: Comparison of ozone measurement methods in biomass burning smoke: an evaluation under field and laboratory conditions, Atmos. Meas. Tech., 14 (3), 1783 - 1800, https://amt.copernicus.org/articles/14/1783/2021/, 2021.

Perma Pure LLC, Compounds Removed by Nafion ${ }^{\mathrm{TM}}$ Tubing Dryers (https://www.permapure.com/environmentalscientific/resources/all-about-nafion-and-faq/). Accessed January 8, 2022.

Singh, H. B., Cai, C., Kaduwela, A., Weinheimer, A., and Wisthaler, A.: Interactions of fire emissions and urban pollution over California: ozone formation and air quality simulations, Atmos. Environ., 56, 45-51, 10.1016/j.atmosenv.2012.03.046, 2012.

Spicer, C.W., Joseph, D.W., and Ollison, W.M.: A re-examination of ambient air ozone monitor interferences, J. Air Waste Manage., 60 (11), 1353-1364, 10.3155/1047-3289.60.11.1353, 2010.

Turnipseed, A.A., Andersen, P.C., Williford, C.J., Ennis, C.A., and Birks, J.W.: Use of a heated graphite scrubber as a means of reducing interferences in UV-absorbance measurements of atmospheric ozone, Atmos. Meas. Tech., 10, 2253 - 2269, https://doi.org/10.5194/amt-10-2253-2017, 2017. 


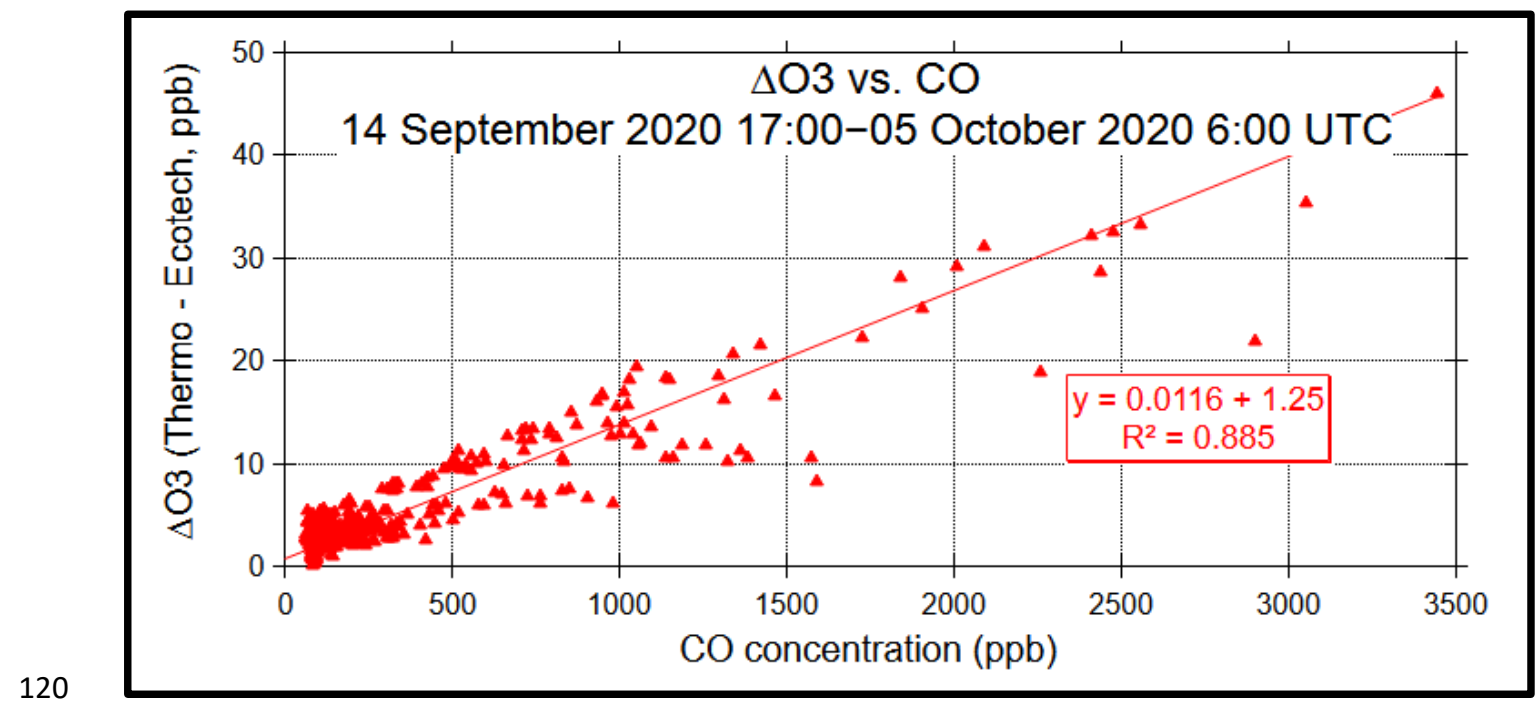

Figure 1: Difference in $\mathrm{O}_{3}$ readings between the Thermo-Fisher and Ecotech $\mathrm{UV}$ instruments vs. CO for a 3-week period starting 14 September 2020. During this period, the Thermo-Fisher instrument gave readings that were up to $50 \mathrm{ppb}$ higher than the Ecotech instrument. Values are hourly averages. 